\title{
Thermal post-buckling improvements of laminated composite plates using the active strain energy tuning approach
}

\begin{abstract}
Shape memory alloy was firstly used commercially as a hydraulic coupling in the Grumman F14A in 1971. It is today used among others to improve structural behaviours such as buckling of composite plates in the aerospace vehicles. In this paper, finite element model and its source code for thermal post-buckling of shape memory alloy laminated composite plates is presented. The shape memory alloy wires induced stress that improved the strain energy, stiffness and thus the buckling behaviour of the composite plates. The finite element formulation catered the combined properties of the composite and shape memory alloys, the addition of the recovery stress and the temperature dependent properties of the shape memory alloys and the composite matrix. This study showed that by embedding shape memory alloy within layers of composite plates, post-buckling behaviours of composite plates can be improved substantially.
\end{abstract}

Keyword: Active strain energy tuning; Laminated composite plates; Nonlinear finite element model; Shape memory alloy; Thermal buckling; Thermal post-buckling 